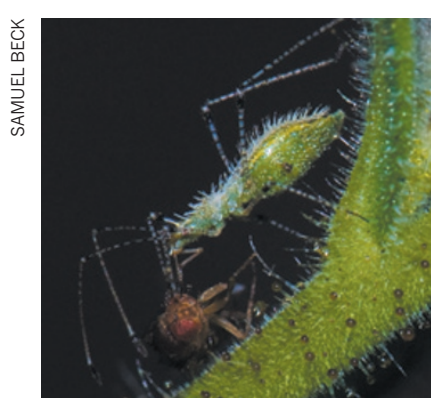

Billy Krimmel at the University of California, Davis, and Ian Pearse at Cornell University in Ithaca, New York, report that sticky, hair-like trichomes on common tarweed (Madia elegans) trap small insects. These may function as bait to attract predatory insects (pictured) that feast on caterpillars, which would damage the plant.

The authors carried out a field experiment in California, and found that adding dead fruitflies to plants increased the abundance of the predators that they surveyed by between $76 \%$ and $450 \%$. Adding bait also reduced bud damage from the most common caterpillar in the ecosystem by $60 \%$, and increased fruit production by $10 \%$.

Ecol. Lett. http://dx.doi. org/10.1111/ele.12032 (2012)

\section{GENETICS}

\section{RNA tails time} protein production

A cell's rhythm of protein production may be regulated by the addition and removal of tails at the end of the messenger RNA molecules that carry the protein recipes.

The cellular circadian clock yields rhythmic patterns in the expression of many genes and the synthesis of their protein products. Carla Green and her colleagues at the University of Texas Southwestern Medical Center in Dallas found 237 mouse-liver mRNAs that show circadian rhythmicity in the number of adenosine molecules added to the end of mRNAs. The length of this 'poly(A) tail' can affect the stability of the mRNA and, ultimately, the amount of cognate protein produced.

Further analysis of five of these mRNAs showed that peak poly(A) tail length preceded a peak in protein accumulation by $4-8$ hours, even when the amount of those mRNAs remained constant.

Genes Dev. 26, 2724-2736 (2012)

\section{MATERIALS}

\section{Grains call a halt with sound}

Granular materials such as sand may slow high-speed projectiles by turning kinetic energy from an incoming object into complex networks of sound waves.

Abram Clark at Duke University in Durham, North Carolina, and his colleagues studied the impact of bronze disks falling onto a bed of photoelastic grains - plastic particles that light up under pressure. Filming at 40,000 frames per second, the team found that falling disks pulsed acoustic energy along branching networks of grains that glowed as pressure travelled through the material (pictured). The 'force chains' decayed exponentially and died out after passing through about 10 particles. Falling disks decelerated in spurts that

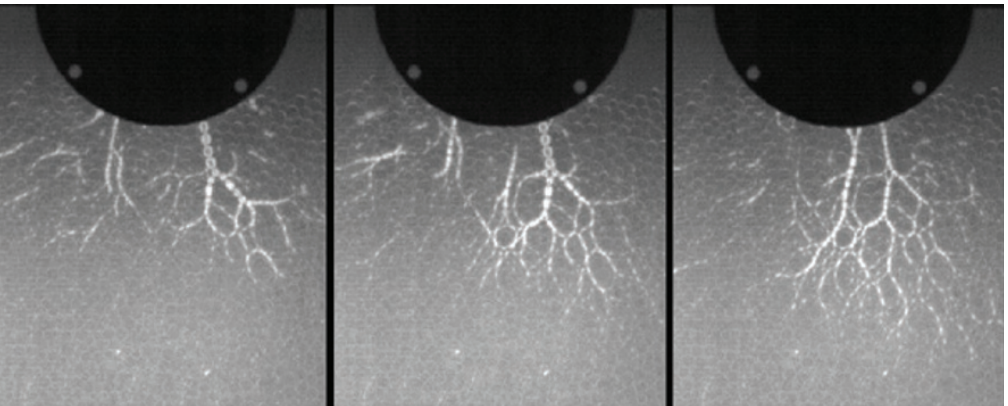

COMMUNITY CHOICE

The most viewed papers in science

\title{
Scarce cetaceans catalogued
}

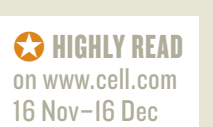

6 Nov-I6 Dec

A paper titled "The world's rarest whale" documents the unprecedented beaching of two spade-toothed beaked whales (Mesoplodon traversii).

Members of this species, which haunt the deepest reaches of the South Pacific Ocean, had been known from only a tiny handful of bones and teeth. A mother and calf stranded in 2010 are thought to be the first to be seen in the flesh. The adult was about five metres long and patterned in black, white and grey. Initially misidentified as Gray's beaked whales (M. grayi), the rare animals were correctly identified thanks to DNA typing by Rochelle Constantine at the University of Auckland in New Zealand and her co-authors.

Curr. Biol. 22, R905-R906 (2012)

matched closely in time with acoustic fluctuations through the grain bed, suggesting that acoustic waves play a key part in dissipating the energy of projectiles that strike granular materials.

Phys. Rev. Lett. 109, 238302

(2012)

\section{GEOLOGY \\ Counting geoneutrinos}

Neutrinos are tiny, nearly massless particles that are generated by nuclear reactions and can fly unimpeded through even the thickest rock. Because of these properties, geologists would like to use geoneutrinos - electron antineutrinos emitted during the decay of natural radionuclides - to estimate the heat generated by radioactivity inside Earth's mantle.

Ondřej Šrámek at the University of Maryland in College Park and his colleagues now present a plan for making measurements of these particles at two or more strategic points in the Pacific Ocean to discriminate between different models of Earth's mantle architecture.

Earth Planet. Sci. Lett. http://dx.doi.org/10.1016/ j.epsl.2012.11.001 (2012)

\section{CANCER \\ Clonal clues reveal cancer chaos}

The general assumption that a tumour cell's behaviour is guided largely by its DNA sequence may be incorrect.

John Dick at the University of Toronto in Canada and his colleagues grew 150 cell populations from individual, labelled cancer cells taken from ten patient-derived colorectal-cancer samples. The researchers transplanted these cells into mice, then tracked their genetics and behaviour as the grafts grew. Tumour-cell clones from the same cell line differed widely in their growth patterns, ability to seed new tumours and response to the cancer drug oxaliplatin.

The results suggest that factors beyond the DNA sequence - such as differences in the chemical groups attached to it, which influence gene expression, or environmental influences shape tumour-cell conduct. Science http://dx.doi.org/ 10.1126/science.1227670 (2012)

\section{$\checkmark$ NATURE.COM}

For the latest research published by Naturevisit:

www.nature.com/latestresearch 